\title{
THE STUDY OF DISSOLVED HELIUM AND RADON CONCENTRATIONS IN GROUNDWATERS OF SOUTHERN PRIBAIKALIE IN CONNECTION WITH SEISMIC PROCESSES
}

\author{
R.M. Semenov ${ }^{1,2}$, M.N. Lopatin ${ }^{1,3}$, V.V. Chechelnitsky ${ }^{4}$ \\ ${ }^{1}$ Institute of the Earth's Crust, Siberian Branch of RAS, Irkutsk, Russia \\ ${ }^{2}$ Irkutsk State Transport University, Irkutsk, Russia \\ ${ }^{3}$ Irkutsk State University, Irkutsk, Russia \\ ${ }^{4}$ Baikal Branch, Geophysical Survey of RAS, Irkutsk, Russia
}

\begin{abstract}
It is known that changes in geochemical fields may be due to the formation and development of earthquake foci. Hydrogeochemical fields at observation sites can be disturbed by underground shocks of sufficient energy, which occur at specific epicentral distances. Our study aimed to reveal these relationships by analysing the concentrations of helium and radon in groundwaters of Southern Pribaikalie, the area around Lake Baikal in Russia. Water samples were taken daily at 10 a.m. from artesian well No. 3 in Zeleny Mys, Irkutsk region. After water sparging, radon concentrations were measured by beta-detection Camera-01 and INGEM-1 (magnetic discharge indicator of helium) to determine helium concentrations. We analysed the concentration values in connection with 22 seismic events that occurred from 2010 to 2016 at the hydrogeochemical observation site (energy classes K of 10.4-14.5; epicentral distances of 40-750 km; conditional energy of $K^{\prime}>6$ ). Based on the radon and helium concentration diagrams, specific regularities were established in the concentration variations before the earthquakes. Generally, concentration variations (increasing/decreasing) in excess of 1.5-2.0 standard deviations preceded earthquakes. This article presents the study results and discusses variations in the radon and helium concentrations, which are due to the seismic process and can be considered as a short-term precursor of earthquakes.
\end{abstract}

KEYWORDS: seismicity; radon; helium; earthquake energy class; epicentral distance; earthquake precursor

FUNDING: The research was supported by RFBR (20-05-00357 A).

FOR CITATION: Semenov R.M., Lopatin M.N., Chechelnitsky V.V., 2020. The study of dissolved helium and radon concentrations in groundwaters of Southern Pribaikalie in connection with seismic processes. Geodynamics \& Tectonophysics 11 (1), 63-74. doi:10.5800/GT-2020-11-1-0463 


\title{
ИЗУЧЕНИЕ КОНЦЕНТРАЦИЙ РАСТВОРЕННЫХ ГЕЛИЯ И РАДОНА В ПОДЗЕМНЫХ ВОДАХ ЮЖНОГО ПРИБАЙКАЛЬЯ В СВЯЗИ С СЕЙСМИЧЕСКИМИ ПРОЦЕССАМИ
}

\author{
P.М. Семенов ${ }^{1,2}$, М.Н. Лопатин ${ }^{1,3}$, В.В. Чечельницкий ${ }^{4}$
}

\author{
${ }^{1}$ Институт земной коры Сибирского отделения РАН, Иркутск, Россия \\ ${ }^{2}$ Иркутский государственный университет путей сообщения, Иркутск, Россия \\ ${ }^{3}$ Иркутский государственный университет, Иркутск, Россия \\ ${ }^{4}$ Байкальский филиал ФИЦ «Единая геофизическая служба РАН», Иркутск, Россия
}

\begin{abstract}
АннотАЦИЯ. Известно, что изменения геохимических полей нередко обусловлены формированием и реализацией очагов землетрясений, причем тех подземных толчков, которые по своему энергетическому классу и эпицентральному расстоянию способны оказывать влияние на гидрогеохимические поля в пунктах наблюдений. С целью установления этих взаимосвязей в Южном Прибайкалье проводятся исследования содержаний растворенных в подземных водах радона и гелия. В качестве пункта наблюдения использовалась артезианская скважина № 3 бывшего профилактория «Зеленый Мыс» (Иркутская область). Пробы воды, отбираемые ежедневно в 10 часов утра, подвергались процессу барботажа и последующему измерению концентраций радона на блоках бета-детектирования комплекса «Камера-01», а также на приборе ИНГЕМ-1 (индикатор гелия магниторазрядный) для определения концентраций гелия. За период с 2010 по 2016 г. нами было рассмотрено 22 сейсмических события с энергетическими классами К от 10.4 до 14.5 и эпицентральными расстояниями от 40 до 750 км, которые проявились в пункте гидрогеохимических наблюдений с условной энергетической характеристикой К'>6. Установлено, что накануне землетрясений в вариациях концентраций обнаруживаются определенные закономерности, которые могут служить предвестниками времени возникновения землетрясений. Они выражаются в своеобразных формах кривых на графиках содержаний радона и гелия. Их вариации, превышающие величину полутора - двух среднеквадратичных отклонений в сторону повышения или понижения концентраций, как правило, предшествовали землетрясениям. В данной статье рассматриваются полученные результаты изменений вариаций вышеуказанных газов, которые обусловлены сейсмическим процессом и могут служить краткосрочным предвестником землетрясений.
\end{abstract}

КЛЮЧЕВЫЕ СЛОВА: сейсмичность; радон; гелий; энергетический класс землетрясений; эпицентральное расстояние; предвестник землетрясений

\section{1. ВВЕДЕНИЕ}

Во многих сейсмоактивных регионах Земли установлены различные вариации гидрогеохимических, гидрогеодинамических, радиометрических и других данных, обусловленных сейсмическим процессом, причем одни из них накануне подземных толчков испытывают повышение своих концентраций, другие, наоборот, понижение, и, наконец, некоторые из них не реагируют на приближение землетрясений, что существенно затрудняет их интерпретацию в качестве предвестников времени землетрясений. Ранее было отмечено, что комплексы предвестников не обладают 100-процентной надежностью, поскольку разные землетрясения могут иметь собственный сценарий подготовки. Более того, на практике данные по разным предвестникам часто противоречивы [Gol'din et al., 2001]. Именно поэтому в настоящее время существует большое количество рекомендаций по поиску предвестников времени возникновения землетрясений. В одних случаях предлагается для прогноза использовать одновременно как можно больше различных данных, в других же, наоборот, считается, что использование данных «кучей», без отсева, способствует укреплению мнения об отсутствии предвестников землетрясений вообще [Dobrovolsky, 2009]. Также нет единого мнения по поводу использования количества пунктов наблюдений за одним конкретным очагом землетрясения. Считается, что наблюдения желательно вести, по крайней мере, на двух и более точках наблюдения [Wyss et al., 1997], что должно повышать достоверность выделения предвестников землетрясений [Kissin, 2009]. Отмеченные различия в поведении предвестников перед землетрясениями обусловлены разными моделями и механизмами их очагов, а также различными геолого-тектоническими особенностями пунктов гидрогеохимических наблюдений. По этому поводу И.Г. Киссиным было предложено вести гидрогеохимические и другие виды наблюдений в так называемых «чувствительных зонах», в которых отмечаются высокоамплитудные предвестники землетрясений, т.е. в зонах тектонических разломов [Kissin, 1988].

По-видимому, именно это обстоятельство не позволило спрогнозировать время возникновения Таншаньского катастрофического землетрясения в Китае в 1976 г. и провести эвакуацию населения, хотя предвестников надвигающейся катастрофы было очень много. Накануне землетрясения отмечались многочисленные предвестники в различных пунктах на большой территории в районе г. Таншань, причем фиксировались они по геологическим, геофизическим, геохимическим, наклономерным и другим данным [Sobolev, 1993; Cicerone et al., 2009]. Еще одним объяснением этого, вероятно, является 
то, что на вариации различных гидрогеохимических и других полей, помимо напряженно-деформированного состояния земной коры, могут влиять и другие факторы, среди которых выделяются «астрономически точные» - приливные процессы, «менее точные»- сезонные колебания и «весьма случайные» - колебания, связанные с изменением погоды [Barsukov et al., 1989]. Но они, как правило, вызывают краткосрочные изменения в геохимических полях, выражающиеся в их единичных отклонениях в сторону повышения или понижения значений содержаний.

Изучение содержаний радона в грунтовых водах Прибайкалья и Забайкалья показало, что на их значения оказывают влияние сезонные вариации метеопараметров [Marenny et al., 2016; Seminsky K.Z., Seminsky A.K., 2016]. В то же время на вариации гидрогеохимических показателей глубинных артезианских вод влияние оказывает напряженно-деформированное состояние земной коры, обусловленное подготовкой и реализацией очагов землетрясений.

Колебания концентраций, связанные с вариациями напряженно-деформированного состояния земной коры обычно продолжаются в течение определенного времени. С целью выявления предвестников времени возникновения землетрясений в Южном Прибайкалье нами проводятся исследования по изучению вариаций концентраций растворенных радона и гелия в подземных водах на артезианской скважине в бывшем санатории «Зеленый Мыс» в 20 км от г. Иркутска.

Характер появления предвестников имеет индивидуальные особенности у каждого землетрясения [Mogi, 1985]. Они определяются конфигурацией сейсмогенных разломов, степенью неоднородности в распределении прочности по плоскости разрыва и типу скольжения. В связи с этим предвестники сильно меняются от района к району и могут повторяться, но далеко не всегда, а лишь на одном и том же разломе, поэтому предыдущее землетрясение в определенной области следует рассматривать как важнейшее указание на то, можно ли ожидать в данной области появления предвестников землетрясений и каких именно. Никакая информация о землетрясениях в других районах и никакой анализ этой информации, особенно о землетрясениях в районах с другим тектоническим строением, не окажут большой помощи в выявлении предвестников в конкретном изучаемом районе.

\section{2. ГИДРОГЕОХИМИЧЕСКИЕ НАБЛЮДЕНИЯ}

Концентрации радона и гелия определяются в пробах воды, отбираемых из самоизливающейся скважины № 3 глубиной 787 м, расположенной на территории бывшего санатория-профилактория «Зеленый Мыс» в 20 км от южного побережья Байкала (рис. 1). Скважина пробурена в грабенообразной долине р. Ангары, расположенной в пределах влияния Ангарского разлома [Khrenov, 1982]. На геологической карте он показан в виде скрытых под четвертичными отложениями тектонических нарушений по обоим берегам р. Ангары, и его наличие подтверждается геофизическими данными: в северо-западной части он выделяется как ось зоны градиентов магнитного поля, а в юго-восточном направлении фрагментарно выражен в виде оси зоны срыва корреляции магнитных аномалий. В гравитационном поле ему отвечает зона градиентов, значения которых увеличиваются с юго-востока на северо-запад. Кроме этого, северо-западная часть разлома подтверждается сейсморазведочными данными. Заложение разлома относится к протерозою, а с позднего мезозоя отмечается его незначительная активизация в связи с тектоническими движениями в южном горном обрамлении Сибирской платформы. Несмотря на то, что сейсмический потенциал Ангарского разлома невысок, он вполне может относиться к «чувствительной зоне» Южного Прибайкалья, в которой могут формироваться высокоамплитудные предвестники землетрясений.

Пробы для измерения концентраций радона и гелия отбираются ежедневно в 10 часов утра. В основу методики измерения объемной активности радона в воде заложен процесс барботажа, создаваемый путем прокачки очищенного атмосферного воздуха в виде мелких пузырей через объемный эквивалент водной пробы, что позволяет вытеснять растворенный радон и сорбировать его в колонке с активированным углем [Methodology..., 1993]. На последующем этапе сорбционная колонка экспонируется в течение трех часов, для того чтобы радон достиг состояния равновесия со своими дочерними продуктами распада: ${ }^{214} \mathrm{~Pb}$ и ${ }^{214} \mathrm{Bi}$, так как измерение производится в блоках бета-детектирования прибора (тип «Камера-01»). Объемная активность радона в воде $\left(C_{\mathrm{Rn}} ;\right.$ Бк/л) вычисляется по измеренной активности в угле (А, Бк) с учетом времени между отбором пробы и началом измерения $(t$, ч) и постоянной распада радона $(\lambda ; 0.007551 / 4)$ :

$$
C_{R n}=0.78 A \exp (\lambda t) \text {. }
$$

Для измерения содержания растворенного гелия в пробах используется прибор ИНГЕМ-1 (индикатор гелия магниторазрядный) [Yanitsky, 1979]. По результатам обработки полученных данных строятся графики вариаций концентраций, что позволяет по характерным формам кривых на графиках фиксировать возможные краткосрочные предвестники землетрясений.

\section{3. ПОИСК ПРЕДВЕСТНИКОВ ЗЕМЛЕТРЯСЕНИЙ}

Время проявления гидрогеохимических предвестников землетрясений зависит, прежде всего, от энергетического класса землетрясений, а также от эпицентрального расстояния и геолого-тектонических условий, в которых расположен пункт гидрогеохимических наблюдений. Для того чтобы количественно оценить это влияние непосредственно в точке наблюдений, В.Л. Барсуков с коллегами [Barsukov et al., 1992] предложили рассчитывать условную энергетическую характеристику, которая позволяет учитывать энергию землетрясения в пункте наблюдений в связи с его удаленностью от эпицентра землетрясения:

$$
K^{\prime}=K-2.5 \lg R,
$$




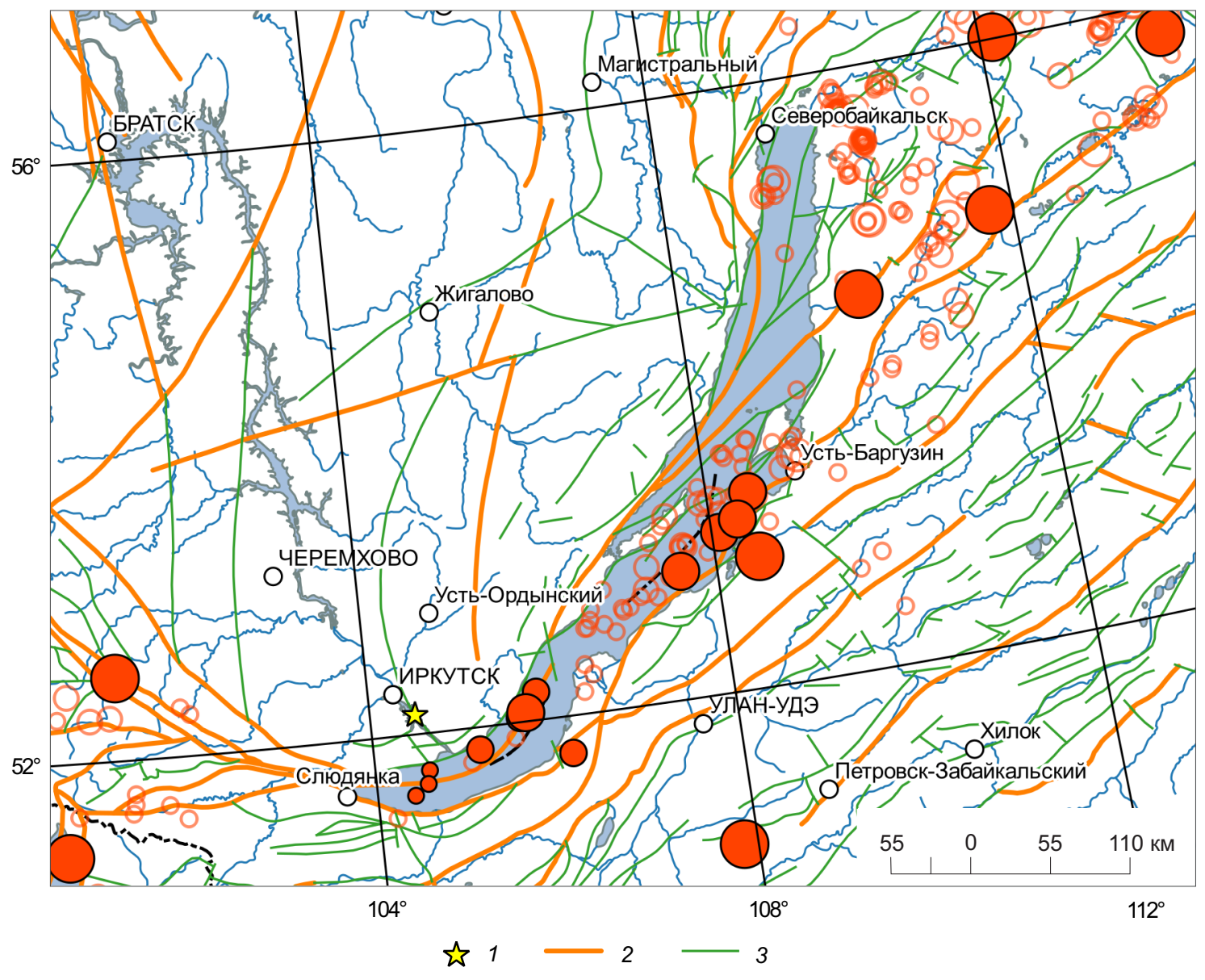

Энергетический класс землетрясений

○10-11 $\bigcirc$ 11-12 $12-13 \bigcirc$ более 13

Энергетический класс проявившихся землетрясений

○ 10-11 $\bigcirc$ 11-12

Рис. 1. Карта разломов и эпицентров землетрясений Прибайкалья (всех событий в период с 2010 по 2017 г. с энергетическим классом K $\geq 10$ и тех, которые проявились в пункте гидрогеохимических наблюдений с условным энергетическим классом K' $\geq 6$ ).

1 - пункт гидрогеохимических наблюдений (скважина № 3, «Зеленый Мыс»); 2 - основные разрывные нарушения; 3 - второстепенные разрывные нарушения.

Fig. 1. The Baikal region map. The map shows the epicenters of $K \geq 10$ earthquakes and seismic events at the hydrogeochemical observation site with the conditional energy class of $K^{\prime} \geq 6$, which occurred from 2010 to 2017.

1 - hydrogeochemical observation site (well No. 3, Zeleny Mys); 2 - major faults; 3 - minor faults.

где $K$ - энергетический класс землетрясений; $K^{\prime}$ - условная энергетическая характеристика сейсмического воздействия на точку гидрогеохимических наблюдений; $R$ - эпицентральное расстояние; 2.5 - коэффициент пропорциональности, полученный численным представлением номограммы Т.Г. Раутиан [Barsukov et al., 1992].

В литературе неоднократно отмечалось [Ulomov, Mavashev, 1967; Rikitake, 1976; Allegri et al., 1983; Asada..., 1982; Barsukov et al., 1985, 1989, 1992; Igarashi, Wakita, 1990; Mogi, 1985; Kissin, 1988, 1993; Voitov, Popov, 1993; Sobolev, 1993; Utkin et al., 2006; Krupoderov, Kulikov, 2008; Dobrovolsky, 2009; Ghosh et al., 2009; Semenov, 2010; Semenov, Smekalin, 2011; Ryabinin, Kuzmin, 2012; Firstov, Makarov, 2015; и дp.], что надежными предвестниками времени возникновения землетрясений являются гидрогеохимические данные на основании исследований концентраций растворенных радона и гелия в подземных водах. Объясняется это тем, что они чутко реагируют на изменения напряжений и деформаций в горных породах перед землетрясениями. Происходит это в результате того, что выделению этих газов из горных пород способствуют ультразвуковые и инфразвуковые колебания, которые сопровождают подготовку очагов землетрясений. Ощутимые колебания растворенного гелия имеют пульсационный вид и короткопериодный характер: от одних до нескольких суток [Gratsinsky et al., 1967; Tyminsky, 1979; Shabynin et al., 1983]. Развитие восходящего дренажа флюидов зависит от пространственно-временного изменения состояния флюидовмещающей среды, темпы которого измеряются короткими интервалами: сутками - первыми месяцами. Это обстоятельство связано с функционированием глобально 
развитого поля напряжений-деформаций. Оно, в свою очередь, выражено в виде периодически возникающих, разрушающихся и замещающих друг друга пространственных короткоживущих структур растяжения и сжатия. Этот процесс охватывает все виды горных пород, что существенно влияет на герметичность недр [Vartanyan, 2000].

Повышение концентраций радона в подземных водах перед землетрясениями объясняется изменением напряженно-деформированного состояния, способствующего его выносу с глубин земной коры с потоком других газов (флюидов), поскольку при обычном диффузионном его переносе (с учетом его периода полураспада - 3.825 суток) такой эффект труднообъясним [Voitov, Popov, 1989]. Более подробно вопрос модели вертикальной скорости переноса газового потока в земной коре рассмотрен в работе П.П. Фирстова и E.0. Макарова [Firstov, Makarov, 2015].

Известно, что в процессе подготовки землетрясения различные параметры горных пород испытывают значительные флуктуации, причем многие из них обладают некоторыми общими свойствами, которые отражаются в гидрогеохимических вариациях, например переход через экстремум [Sobolev, 1993]. При этом нередко такие вариации возникают за несколько дней или недель до землетрясения и могут служить среднесрочным предвестником, а затем за несколько часов или первые дни до сейсмического события - краткосрочным предвестником. Подобные явления неоднократно отмечались в различных сейсмических регионах. Так, по данным гидрогеосейсмологических наблюдений в северо-восточной части Байкальской рифтовой зоны установлено, что за 5-15 суток до землетрясения отмечается изменение некоторых компонентов ионно-солевого состава подземных вод, которое прекращается в течение первых суток после подземного толчка [Shabynin et al., 1983]. По наблюдениям В.И. Уткина с коллегами за вариациями поля радона его заметные изменения наблюдались за 90-100 дней до сейсмического события, а характерные - за 3-5 дней. Само же землетрясение произошло спустя 48 часов после достижения максимума концентрации радона [Utkin et al., 2006]. По нашим данным, падение концентрации растворенного гелия в глубинной воде Байкала началось за три недели до Култукского землетрясения 2008 г. с M=6.3 и прекратилось за два дня до сейсмического толчка [Semenov, 2010]. Подобные вариации концентраций растворенного гелия в подземных водах в это время отмечались и в скважине, расположенной в пос. Зеленый Мыс (рис. 2). По мнению Э.М. Прасолова, близповерхностные флюиды дают о себе знать за день до землетрясения [Prasolov, 1990]. В статье [Cicerone et al., 2009] приведены мировые данные по различным газовым эмиссиям, обусловленным землетрясениями. Анализ этих данных показывает, что перед подземными толчками концентрации Rn и Не характеризуются различными значениями и продолжительностью проявления предвестников в зависимости от магнитуд и эпицентральных расстояний [Cicerone et al., 2009].

Исследования гидрогеодинамических данных, обусловленных сейсмичностью, показали, что эффекты предвестники землетрясений - имеют различные формы кривых (рис. 3), которым, по мнению И.Г. Киссина, соответствуют и другие геофизические поля [Kissin, 1993, 1997; Kissin, Grinevsky, 1990]. При этом выделяются формы кривых на графиках, которые чаще других отражают воздействия землетрясений на различные геофизические поля. К ним относятся «бухтообразные» (рис. 3, a) и «ступенчатые» (рис. 3, б) с повышением или понижением исследуемой величины.

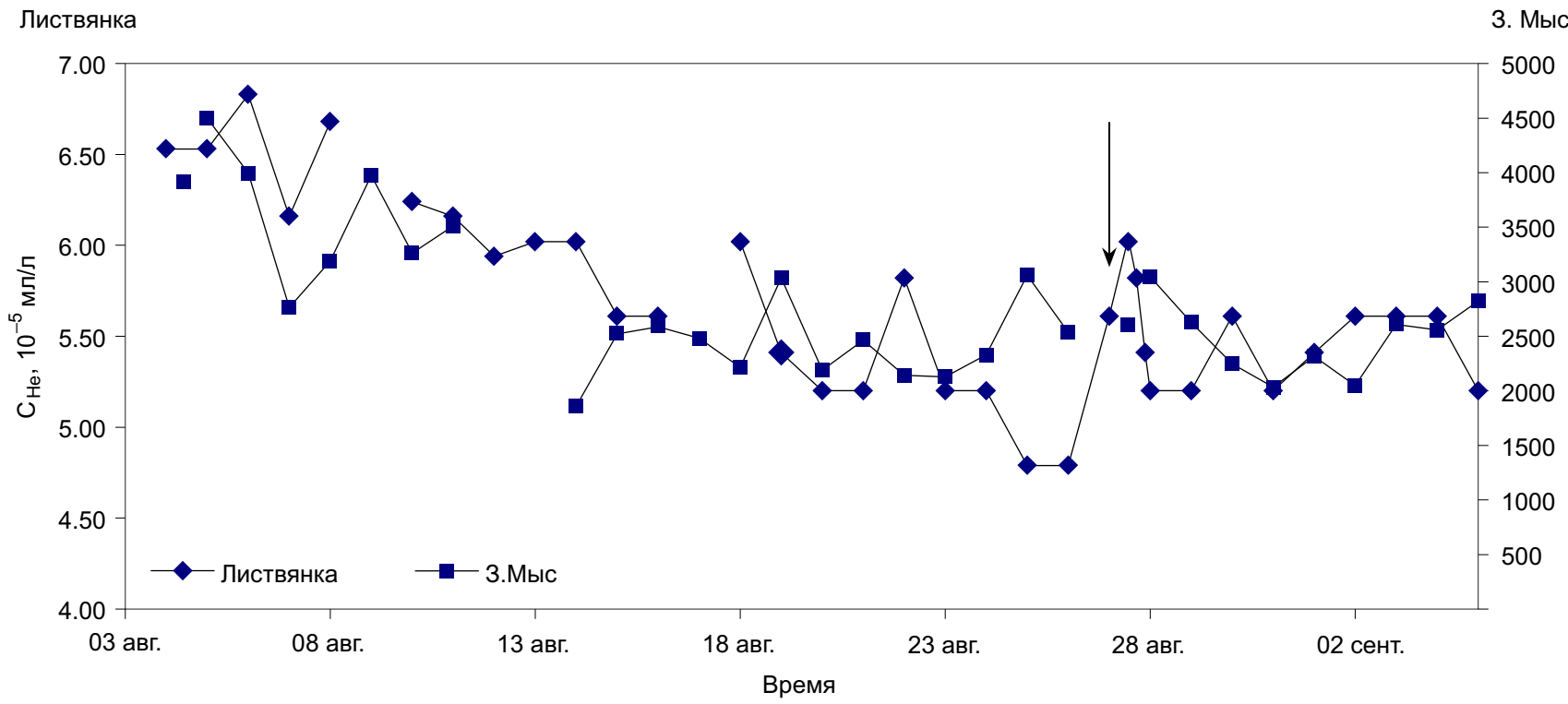

Рис. 2. График изменений концентраций растворенного гелия в глубинной воде Байкала в п. Листвянка и в подземной воде из скважины в п. Зеленый Мыс накануне Култукского землетрясения 27 августа 2008 г.

Fig. 2. Concentrations of dissolved helium in the depth water sample from Lake Baikal (Listvyanka village) and the groundwater sample from the well in Zeleny Mys settlement before the Kultuk earthquake of August 27, 2008. 


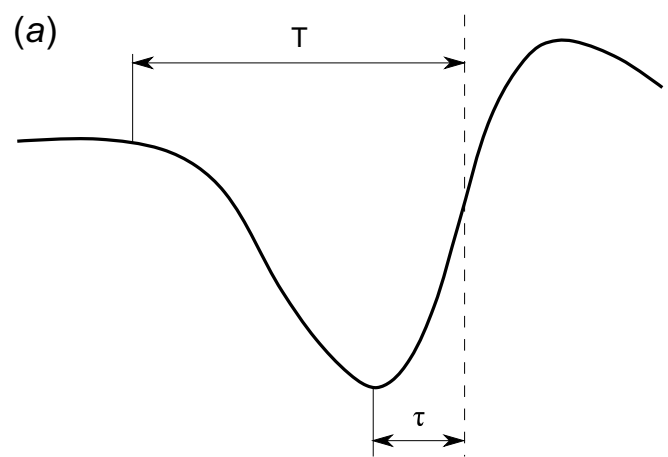

(8)

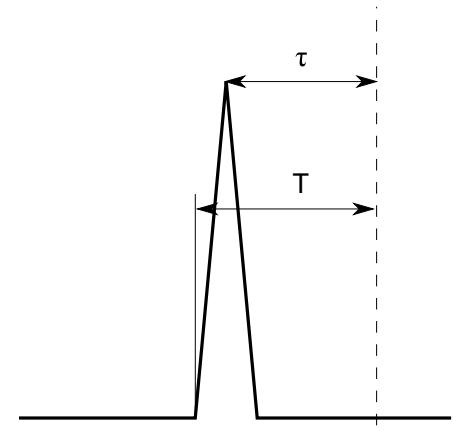

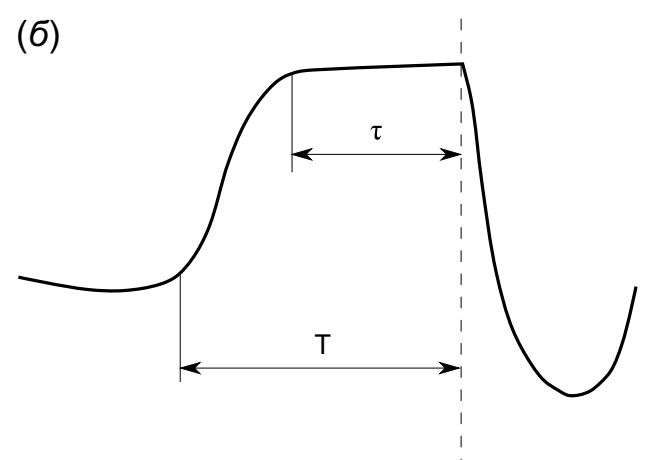

(2)

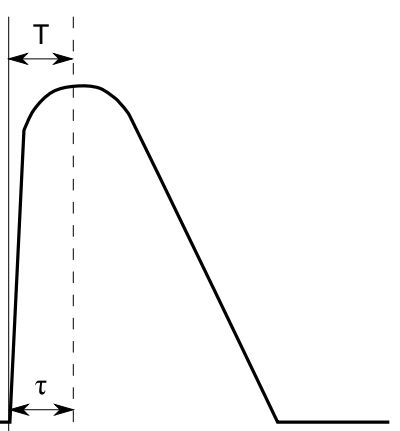

Рис. 3. Основные типы гидрогеохимических предвестниковых эффектов землетрясения.

По оси ординат - изменение концентраций газов в подземных водах, по оси абсцисс - время до землетрясения: (a) - бухтообразные, (б) - ступенчатые, ( 8 ) - импульсные, (2) - скачкообразные. Т - время среднесрочного предвестника - это начало изменения знака или скорости деформации, т. е. наступление новой стадии в процессе подготовки землетрясения, $\tau$ - время экстремума (период от перегиба кривой изменения знака или скорости на графике до момента землетрясения), т. е. время краткосрочного предвестника. Пунктирной линией обозначен условный момент землетрясения [Kissin, 1997; Ryabinin, Kuzmin, 2012; Ryabinin, Khatkevich, 2008].

Fig. 3. The main types of hydrogeochemical precursor effects.

Y-axis - gas concentration variations in groundwater; X-axis - time before earthquakes: $(a)$ - bay-type, (б) - stepwise, ( $(6)$ - impulsive, (2) - abrupt. T - time of a medium-term precursor, i.e. start of a change in sign or strain rate (start of a new phase in preparation of an earthquake), $\tau$ - time of an extremum (period from the bend of the sign (or strain rate) change curve before an earthquake), i.e. time of a short-term precursor. A dashed line marks a conditional earthquake moment [Kissin, 1997; Ryabinin, Kuzmin, 2012; Ryabinin, Khatkevich, 2008].

Ранее установленные вариации концентраций гелия в глубинной воде Байкала перед Култукским 2008 г. и рядом других землетрясений Южного Прибайкалья тоже характеризовались подобными формами кривых [Semenov, Smekalin, 2011; Semenov, Lopatin, 2013]. И, как выяснилось, кривые на графиках, характеризующих вариации концентраций радона и гелия в подземных водах Южного Прибайкалья, в связи с сейсмичностью также в основном соответствуют этой закономерности (рис. $4, a$, б).

\section{4. ПОЛУЧЕННЫЕ РЕЗУЛЬТАТЫ}

С учетом того, что перед землетрясениями в Южном Прибайкалье в вариациях концентраций растворенных в подземных водах гелия и радона были обнаружены определенные закономерности, обусловленные экстремумами на графиках, мы рассматриваем их в качестве предвестников землетрясений. Поскольку наши исследования направлены на поиски краткосрочных предвестников землетрясений, мы рассматривали изменения концентраций радона и гелия за несколько суток до подземного толчка. Именно в этот промежуток времени были отмечены экстремумы на графиках вариаций их содержаний, продолжительность времени от которых до сейсмического толчка, на наш взгляд, и соответствует краткосрочному предвестнику.

За период с 2010 по 2016 г. нами было рассмотрено 22 сейсмических события с энергетическими классами К от 10.4 до 14.5 с эпицентральными расстояниями от 40 до 750 км (по данным БФ ФИЦ ЕГС РАН, http:// www.seis-bykl.ru), которые проявились в пункте гидрогеохимических наблюдений с условной энергетической характеристикой $\mathrm{K}^{\prime} \geq 6$. Все они предварялись вариациями концентраций радона и гелия в подземных водах (таблица). Землетрясений с $\mathrm{K}^{\prime} \geq 6$ в пункте гидрогеохимических наблюдений, которые не предварялись гидрогеохимическими вариациями, за рассматриваемый временной интервал не было.

Ранее А.Я. Сидориным было предложено рассчитывать корреляционную зависимость между функцией $\lg T R$ (произведение времени предвестника землетрясения на его эпицентральное расстояние) и энергетическим 

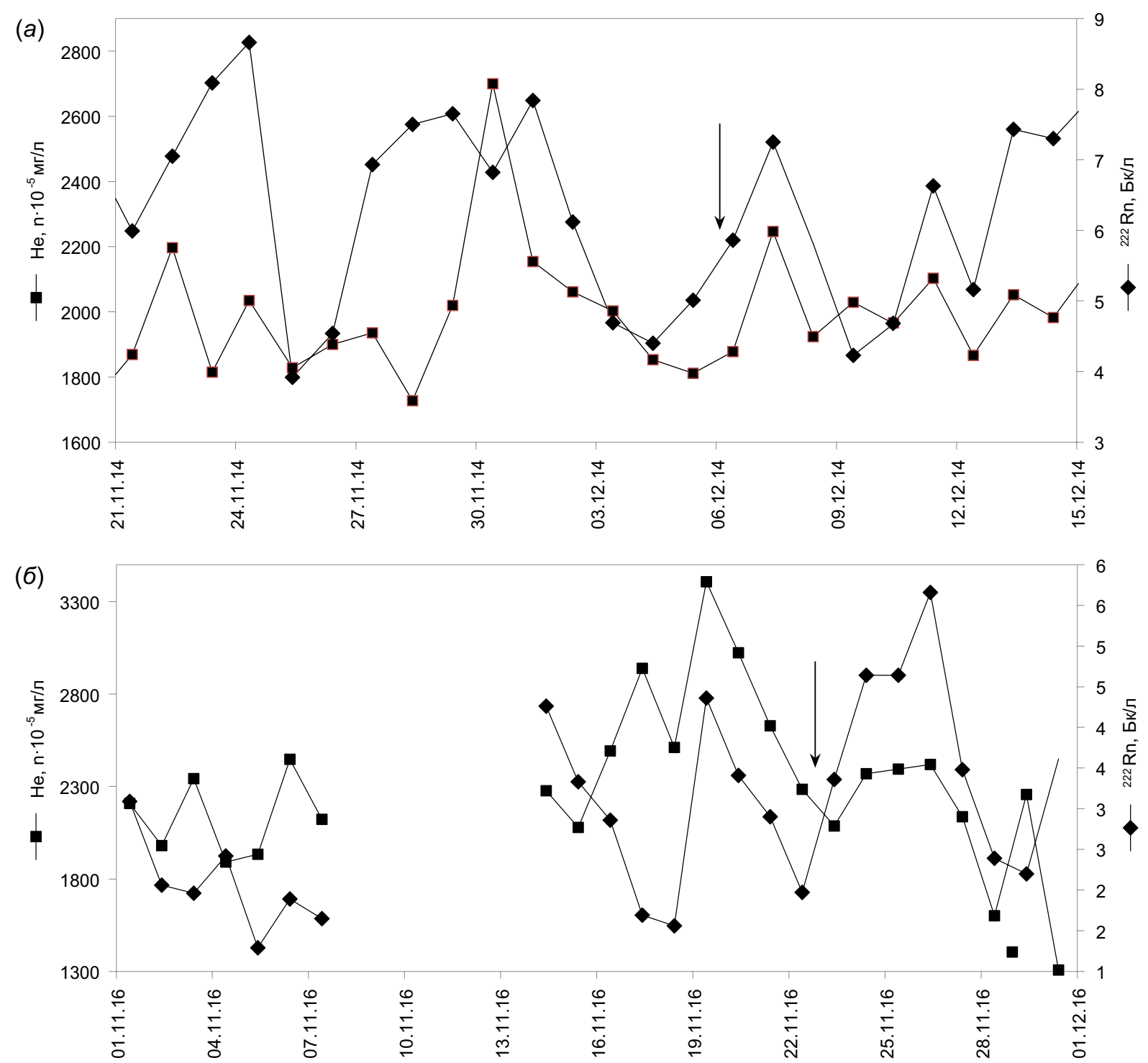

Рис. 4. Характерные кривые изменений концентраций радона и гелия в подземных водах Южного Прибайкалья накануне, во время и после землетрясений: (a) - 12 мая 2014 г.; (б) - 22 ноября 2016 г.

Сейсмические моменты показаны вертикальными стрелками, время которых на графике соответствует местному времени (UTC +8:00).

Fig. 4. Characteristic curves of radon and helium concentration variations in the groundwaters of Southern Pribaikalie before, during and after the earthquakes of May 12, 2014 (a) and November 22, 2016 (б).

Vertical arrows mark the moments of seismic events (local time UTC+8:00).

классом землетрясений по различным видам предвестников [Sidorin, 1979]. При этом он учитывал предвестники по мере их обнаружения, т.е. без разделения их по времени на долго-, средне- и краткосрочные.

С использованием полученных данных по концентрациям растворенных газов в подземных водах и их вариациям в Южном Прибайкалье, обусловленным сейсмическим процессом, мы построили графики и рассчитали корреляционные зависимости функций $\lg \tau R$ от энергетических классов землетрясений. При этом в качестве краткосрочного предвестника землетрясения мы использовали отрезок времени от экстремума ( $\tau$ - период от перегиба кривой изменения знака или скорости на графике) до момента землетрясения:

$$
\lg \tau R=0.30 K-0.98,
$$

коэффициент корреляции $\mathrm{r}=0.88$, стандартная ошибка $\mathrm{s}=0.19$ единиц логарифма для гелия и

$$
\lg \tau R=0.33 K-1.41,
$$

коэффициент корреляции $\mathrm{r}=0.83$, стандартная ошибка s=0.19 единиц логарифма для радона (рис. 5). На рис. 5 дополнительно показано значение по гелию для Култукского землетрясения 2008 г. Оно попадает в 95\%-ный доверительный интервал соотношения (1), что доказывает правомочность его использования.

По соотношениям (1) и (2) мы рассчитали время обнаружения предвестника землетрясения с вероятностью 0.975 в зависимости от его энергетического класса для Южного Прибайкалья (рис. 6) и эпицентрального расстояния (рис. 7) по гелию и по радону. 
Землетрясения Южного Прибайкалья, условная энергетическая характеристика которых в пункте гидрогеохимических наблюдений составляла К' $\geq 6$

Earthquakes in Southern Pribaikalie. Conditional energy $K^{\prime} \geq 6$

\begin{tabular}{|c|c|c|c|c|c|c|c|c|c|c|c|}
\hline \multirow[b]{3}{*}{$\begin{array}{l}\text { Номер, } \\
\text { п/п }\end{array}$} & \multirow[b]{3}{*}{$\begin{array}{c}\text { Дата } \\
\text { землетрясения }\end{array}$} & \multirow[b]{3}{*}{$\begin{array}{c}\text { Время } \\
\text { (по Гринвичу) }\end{array}$} & \multirow{3}{*}{ ясения } & \multirow[b]{3}{*}{ в.д. } & \multirow[b]{3}{*}{ K } & \multirow[b]{3}{*}{$\mathrm{R}$, км } & \multirow[b]{3}{*}{$K^{\prime \prime}$} & \multicolumn{4}{|c|}{ Предвестники } \\
\hline & & & & & & & & \multicolumn{2}{|c|}{$\begin{array}{c}\text { Время } \\
\text { экстремума, } \\
\tau, \text { сутки }\end{array}$} & \multicolumn{2}{|c|}{$\begin{array}{c}\text { Функция, } \\
\operatorname{Lg}(\tau R)\end{array}$} \\
\hline & & & & & & & & $\begin{array}{c}\text { По } \\
\text { гелию }\end{array}$ & $\begin{array}{c}\text { По } \\
\text { радону }\end{array}$ & $\begin{array}{c}\text { По } \\
\text { гелию }\end{array}$ & $\begin{array}{c}\text { По } \\
\text { радону }\end{array}$ \\
\hline 1 & 20100225 & $04: 27$ & 52.19 & 105.84 & 11.7 & 90 & 6.8 & 3.5 & 1.0 & 2.50 & 1.95 \\
\hline 2 & 20100319 & 09:30 & 54.50 & 110.08 & 13.6 & 455 & 6.9 & 2.5 & 2.5 & 3.06 & 3.06 \\
\hline 3 & 20100927 & $13: 00$ & 53.32 & 108.47 & 12.6 & 298 & 6.4 & 2.5 & 3.5 & 2.87 & 3.02 \\
\hline 4 & 20110201 & $12: 53$ & 50.98 & 107.85 & 13.2 & 263 & 7.1 & 2.5 & 5.5 & 2.82 & 3.16 \\
\hline 5 & 20110716 & $18: 38$ & 52.88 & 108.49 & 14.5 & 282 & 8.4 & 5.0 & 3.5 & 3.15 & 2.99 \\
\hline 6 & 20111109 & $15: 23$ & 52.03 & 105.63 & 11.2 & 77 & 6.6 & 1.5 & 3.5 & 2.06 & 2.43 \\
\hline 7 & 20120112 & $04: 45$ & 51.75 & 106.16 & 11.7 & 120 & 6.5 & 4.0 & 2.0 & 2.68 & 2.38 \\
\hline 8 & 20120826 & $10: 43$ & 51.75 & 104.59 & 10.4 & 41 & 6.4 & 4.5 & 5.5 & 2.26 & 2.42 \\
\hline 9 & 20130108 & $11: 51$ & 51.85 & 105.16 & 11.2 & 53 & 7.0 & 2.5 & 2.5 & 2.12 & 2.12 \\
\hline 10 & 20130708 & 09:20 & 51.66 & 104.56 & 10.3 & 50 & 6.1 & 3.0 & 2.0 & 2.18 & 2.00 \\
\hline 11 & 20140425 & 01:44 & 51.59 & 104.41 & 10.5 & 60 & 6.0 & 3.0 & 2.0 & 2.25 & 2.10 \\
\hline 12 & 20140901 & $20: 10$ & 50.86 & 103.27 & 11.5 & 164 & 6.0 & 2.5 & 1.0 & 2.61 & 2.22 \\
\hline 13 & 20141101 & $00: 51$ & 52.56 & 101.25 & 13.6 & 227 & 7.7 & 3.5 & 3.0 & 2.90 & 2.83 \\
\hline 14 & 20141205 & $18: 04$ & 51.37 & 100.63 & 13.9 & 290 & 7.7 & 5.5 & 4.5 & 3.19 & 3.11 \\
\hline 15 & 20141222 & 03:05 & 53.08 & 108.09 & 12.2 & 264 & 6.2 & 1.5 & 1.5 & 2.60 & 2.60 \\
\hline 16 & 20150406 & $07: 47$ & 53.15 & 108.31 & 12.7 & 281 & 6.6 & 3.0 & 5.0 & 2.92 & 3.15 \\
\hline 17 & 20150905 & 05:00 & 52.06 & 105.70 & 12.4 & 81 & 7.6 & 5.0 & 5.0 & 2.61 & 2.61 \\
\hline 18 & 20150925 & $23: 24$ & 54.89 & 111.74 & 13.1 & 568 & 6.2 & 3.5 & 5.0 & 3.29 & 2.61 \\
\hline 19 & 20160203 & $18: 27$ & 52.86 & 107.60 & 12.7 & 225 & 6.8 & 3.5 & 3.5 & 3.00 & 3.00 \\
\hline 20 & 20160213 & $20: 31$ & 56.01 & 112.16 & 13.1 & 660 & 6.0 & 4.0 & 4.0 & 3.42 & 3.42 \\
\hline 21 & 20161122 & $11: 37$ & 55.81 & 114.11 & 13.9 & 750 & 6.7 & 3.5 & 3.5 & 3.42 & 3.42 \\
\hline 22 & 20171018 & $17: 46$ & 50.34 & 105.00 & 12.7 & 201 & 6.9 & 2.5 & - & 2.70 & - \\
\hline
\end{tabular}

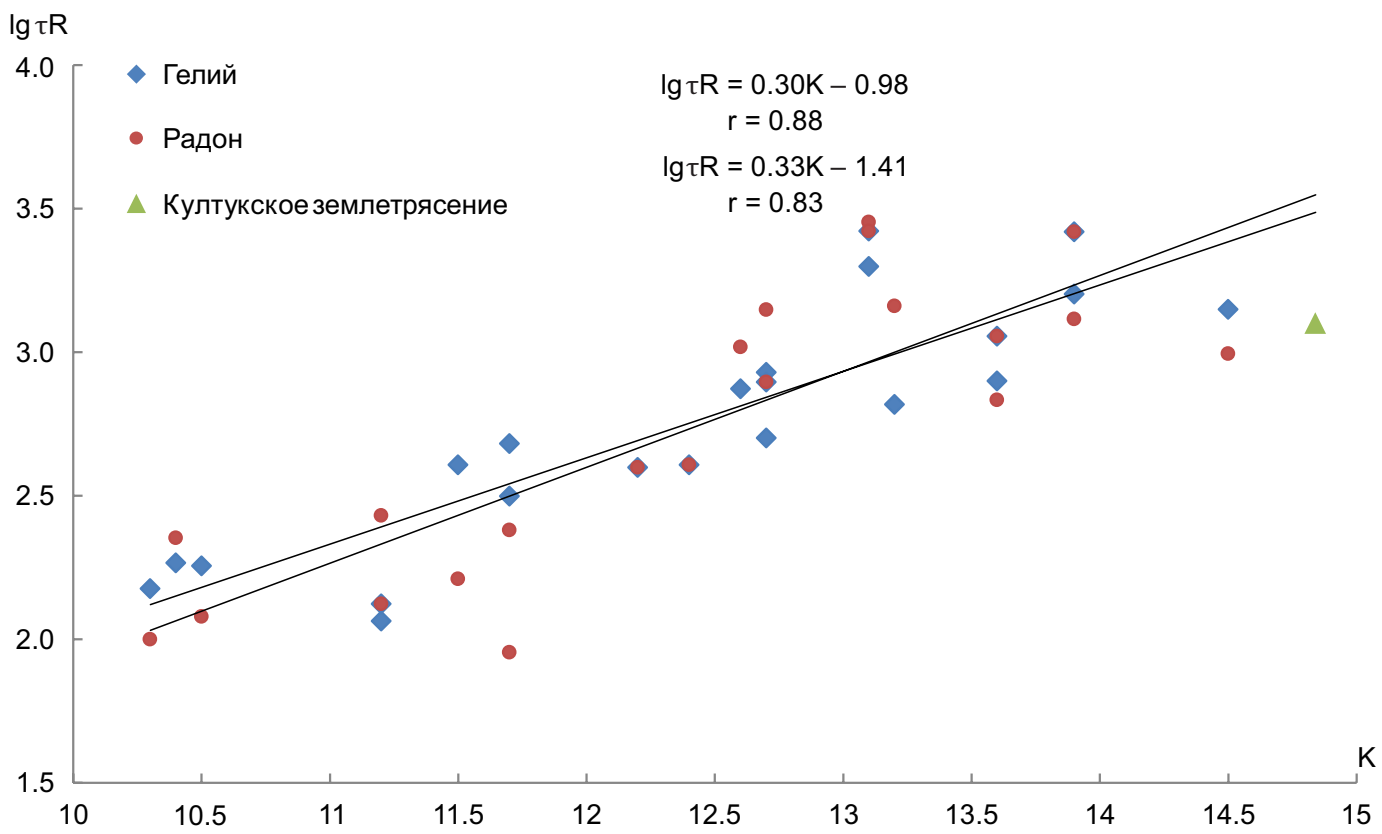

Рис. 5. Зависимость функции $\lg \tau \mathrm{R}$ от энергетического класса землетрясения для Южного Прибайкалья.

Fig. 5. Function $\lg \tau \mathrm{R}$ vs earthquake energy class (Southern Pribaikalie). 


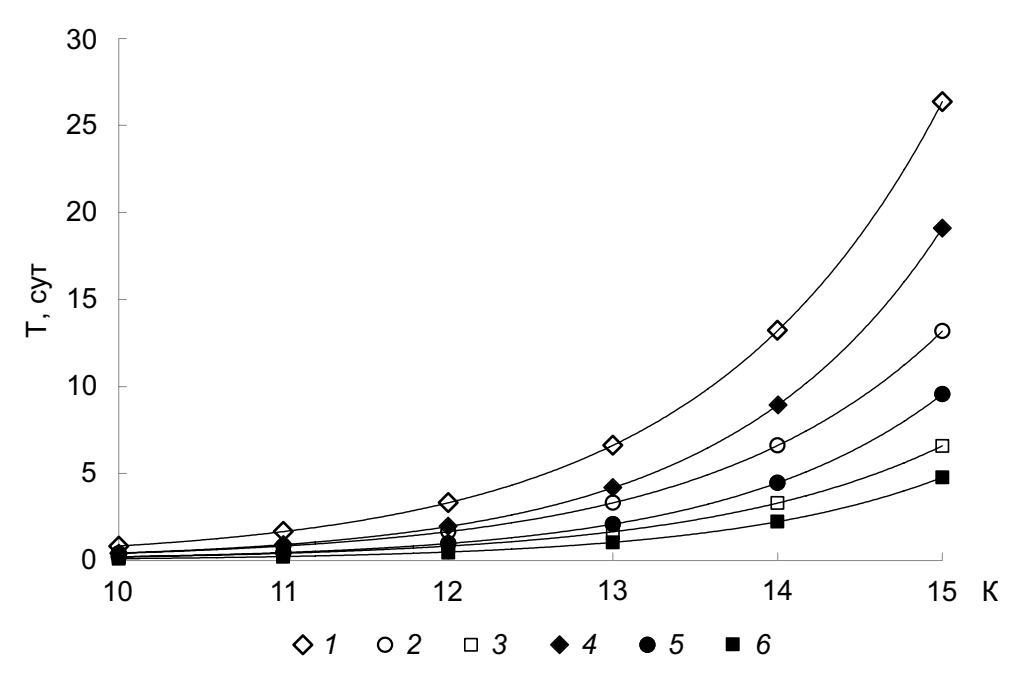

Рис. 6. Расчетное время обнаружения предвестника землетрясения с вероятностью 0.975 в зависимости от его энергетического класса (К) для Южного Прибайкалья при эпицентральном расстоянии $\mathrm{R}=50,100$ и 200 км.

1 - R=50, гелий; 2 - R=100, гелий; 3 - R=200, гелий; 4 - R=50, радон; 5 - R=100, радон; 6 - R=200, радон.

Fig. 6. Earthquake precursor detection time estimated for Southern Pribaikalie, depending on energy class K. Probability $=0.975$. $\mathrm{R}$ - epicentral distance, $\mathrm{km} ; 1-\mathrm{R}=50$, helium; 2 - R=100, helium; 3 - R=200, helium; 4 - R=50, radon; 5 - R=100, radon; 6 $\mathrm{R}=200$, radon.

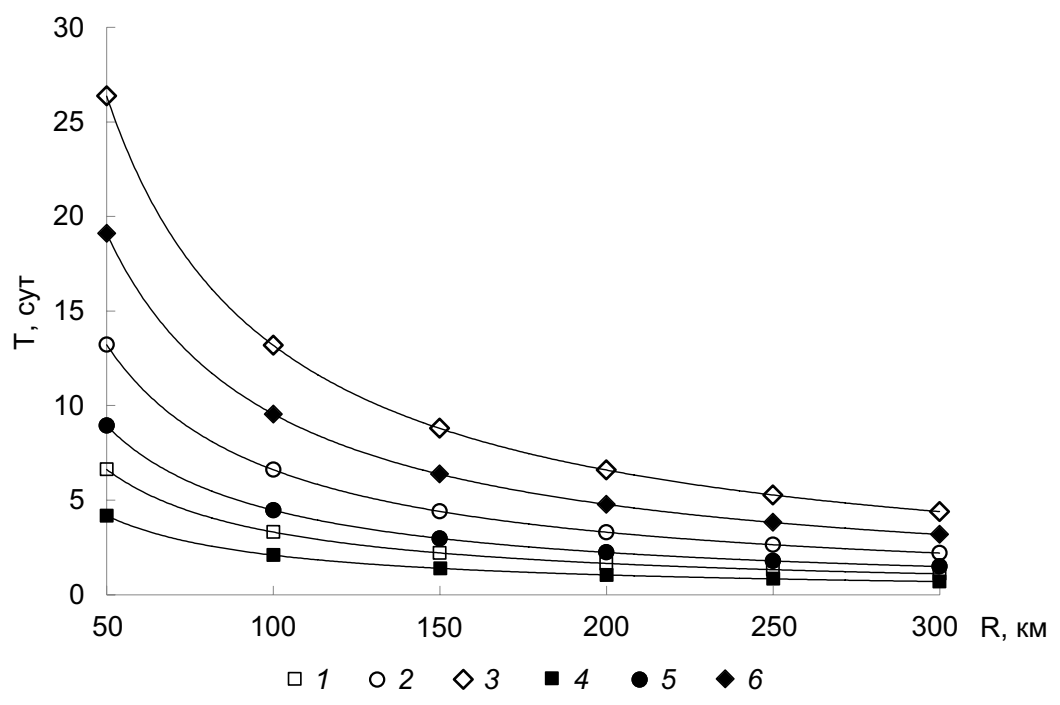

Рис. 7. Расчетное время обнаружения предвестника землетрясения с вероятностью 0.975 в зависимости от его эпицентрального расстояния (R) для Южного Прибайкалья с энергетическим классом К=13-15.

1 - K=13, гелий; 2 - K=14, гелий; 3 - K=15, гелий; 4 - K=13, радон; 5 - K=14, радон; 6 - K=15, радон.

Fig. 7. Earthquake precursor detection time estimated for Southern Pribaikalie, depending on epicentral distance R. Energy class $\mathrm{K}=13-15$. Probability $=0.975$.

$1-\mathrm{K}=13$, helium; $2-\mathrm{K}=14$, helium; $3-\mathrm{K}=15$, helium; $4-\mathrm{K}=13$, radon; 5 - K=14, radon; $6-\mathrm{K}=15$, radon.

\section{5. ЗАКЛЮЧЕНИЕ}

Изучение концентраций радона и гелия, растворенных в подземных водах Южного Прибайкалья, позволило выявить их своеобразные вариации накануне подготовки и реализации очагов землетрясений. Они выражаются в формах кривых изменений концентраций в сторону повышения или снижения их содержаний относительно фоновых значений. Продолжительность времени от характерной точки перегиба до сейсмического события может служить краткосрочным предвестником землетрясения и рассчитывается из полученных уравнений для различных энергетических классов и эпицентральных расстояний землетрясений:

$$
\begin{gathered}
\lg \tau=0.30 K-\lg R-0.98 \pm 0.19 \text { (по радону) и } \\
\lg \tau=0.33 K-\lg R-1.41 \pm 0.19 \text { (по гелию). }
\end{gathered}
$$

Построенные графики (рис. 6, 7) позволяют определить расчетное время предвестников землетрясений по их энергетическим классам и эпицентральным расстояниям. 


\section{6. ЛИТЕРАTУPA/REFERENCES}

Allegri L., Bella F., Della Monica G., Ermini A., Improta S., Sgrigna V., Biagi P.F, 1983. Radon and rilt anomalies detected before the Irpinia (south Italy) earthquake of November 23,1980 at great distances from the epicenter. Geophysical Research Letters 10 (4), 269-272. https://doi.org/ 10.1029/gl010i004p00269.

Asada T. (Ed.), 1982. Earthquake Prediction Techniques: Their Application in Japan. University of Tokyo Press, Tokyo, 317 р. [Русский перевод: Методы прогноза землетрясений: их применение в Японии / Ред. Т. Асада. М.: Недpa, 1984. 312 c.].

Barsukov V.L., Belyaev A.A., Bakaldin Yu.A., Igumnov V.A., Ibragimova T.L., Serebrennikov V.S., Sultankhodzhaev A.N., 1992. Geochemical Methods for Earthquake Forecasting. Nauka, Moscow, 213 p. (in Russian) [Барсуков В.Л., Беляев А.А., Бакалдин Ю.А., Игумнов В.А., Ибрагимова Т.Л., Серебренников В.С., Султанходжаев А.Н. Геохимические методы прогноза землетрясений. М.: Наука, 1992. 213 с.].

Barsukov V.L., Belyaev A.A., Serebrennikov V.S., 1989. Precursors of Disaster (Search for Means of Geochemical Forecasting of Earthquakes). Nauka, Moscow, 136 p. (in Russian) [Барсуков В.Л., Беляев А.А., Серебренников В.С. Вестники беды (о поиске средств геохимического прогноза землетрясений). М.: Наука, 1989. 136 с.].

Barsukov V.L., Varshal G.M., Garanin A.V., Zamokina N.S., 1985. The significance of hydrogeochemical methods for short-term earthquake prediction. In: Hydrogeochemical precursors of earthquakes. Nauka, Moscow, p. 3-16 (in Russian) [Барсуков В.Л., Варшал Г.М., Гаранин А.В., Замокина Н.С. Значение гидрогеохимических методов для краткосрочного прогноза землетрясений // Гидрогеохимические предвестники землетрясений. М.: Наука, 1985. C. 3-16].

Cicerone R.D., Ebel J.E., Britton J., 2009. A systematic compilation of earthquake precursors. Tectonophysics 476 (3-4), 371-396. https://doi.org/10.1016/j.tecto.20 09.06.008.

Dobrovolsky I.P., 2009. Mathematical Theory of Preparation and Prediction of Tectonic Earthquake. FIZMATLIT, Moscow, 240 p. (in Russian) [Добровольский И.П. Математическая теория подготовки и прогноза тектонического землетрясения. М.: ФИЗМАТЛИТ, 2009. 240 с.].

Firstov P.P., Makarov E.O., 2015. Reaction of radon in soil and groundwater to stress-strain state of the Earth's crust. Seismic Instruments 51 (4), 58-80 (in Russian) [Фирстов П.П., Макаров Е.О. Реакция подпочвенного и растворенного в подземных водах радона на изменение напряженно-деформированного состояния земной коры // Сейсмические приборы. 2015. Т. 51. № 4. C. 58-80].

Ghosh D., Deb A., Sengupta R., 2009. Anomalous radon emission as precursor of earthquake. Journal of Applied Geophysics 69 (2), 67-81. https://doi.org/10.1016/j.japp geo.2009.06.001.

Gol'din S.V., Dyad'kov P.G., Dashevskii Y.A., 2001. The South Baikal geodynamic testing ground: strategy of earthquake prediction. Geologiya i Geofizika (Russian Geology and Geophysics) 42 (10), 1484-1496.
Gratsinsky V.G., Gorbushina L.V., Tyminsky V.G., 1967. On the release of radioactive gases from rock samples under the influence of ultrasound. Fizika Zemli (10), 91-94 (in Russian) [Грацинский В.Г., Горбушина Л.В., Тыминский В.Г. О выделении радиоактивных газов из образцов горных пород под воздействием ультразвука // Физика Земли. 1967. № 10. C. 91-94].

Igarashi G., Wakita H., 1990. Groundwater radon anomalies associated with earthquakes. Tectonophysics 180 (2-4), 237-254. https://doi.org/10.1016/0040-1951 (90)90311-u.

Khrenov P.M. (Ed.), 1982. Map of Faults of Southern East Siberia. Scale 1:1500000. VSEGEI, Leningrad (in Russian) [Карта разломов юга Восточной Сибири. Масштаб 1:1500000 / Ред. П.М. Хренов. Л.: ВСЕГЕИ, 1982].

Kissin I.G., 1988. High-amplitude precursors of earthquakes and 'sensitive crustal zones'. Fizika Zemli (6), 3-13 (in Russian) [Киссин И.Г. Высокоамплитудные предвестники землетрясений и «чувствительные зоны» земной коры // Физика Земли. 1988. № 6. С. 3-13].

Kissin I.G., 1993. Hydrogeological monitoring of the Earth's crust. Fizika Zemli (8), 58-69 (in Russian) [Киссин И.Г. Гидрогеологический мониторинг земной коры // Физика Земли. 1993. № 8. С. 58-69].

Kissin I.G., 1997. Relations between forerunners of earthquakes and postseismic effects. Transactions (Doklady) of the Russian Academy of Sciences / Earth Science Sections 355 (5), 736-739.

Kissin I.G., 2009. Vibes in the Earth's Crust: Geophysical and Tectonic Aspects. Nauka, Moscow, 328 p. (in Russian) [Киссин И.Г. Флюиды в земной коре: геофизические и тектонические аспекты. М.: Наука, 2009. 328 с.].

Kissin I.G., Grinevsky A.O., 1990. Main features of hydrogeodynamic earthquake precursors. Tectonophysics 178 (2-4), 277-286. https://doi.org/10.1016/0040-1951 (90)90154-z.

Krupoderov V.S., Kulikov G.V., 2008. On the methodology of short-term earthquake forecasting. Subsoil Exploration and Protection (8), 44-48 (in Russian) [Круподеров B.C., Куликов Г.В. О методологии краткосрочного прогноза землетрясений // Разведка и охрана недр. 2008. № 8. C. 44-48].

Marenny A.M., Tsapalov A.A., Miklyaev P.S., Petrova T.B., 2016. Regularities of Formation of Radon Field in Geological Medium. Pero Publishing House, Moscow, 394 p. (in Russian) [Маренный А.М., Цапалов А.А., Микляев П.С., Петрова Т.Б. Закономерности формирования радонового поля в геологической среде. М.: Изд-во «Перо», 2016. 394 c.].

Methodology for Measuring Radium and Radon Concentrations in Natural Waters. 1993. RTC Niton, Moscow, 6 p. (in Russian) [Методика измерений содержания радия и радона в природных водах. М.: НТЦ «Нитон», 1993. 6 c.].

Mogi K., 1985. Earthquake Prediction. Academic Press, Tokyo, $355 \mathrm{p}$.

Prasolov E.M., 1990. Isotopic Geochemistry and Origin of Natural Gases. Nedra, Leningrad, 283 p. (in Russian) [Прасолов Э.М. Изотопная геохимия и происхождение природных газов. Л.: Недра, 1990. 283 с.]. 
Rautian T.G., 1964. On determining the energy of earthquakes at a distance up to $3000 \mathrm{~km}$. Proceedings of the Institute of Physics of the Earth, USSR Acad. Sci. 32 (199), 88-93 (in Russian) [Раутиан Т.Г. Об определении энергии землетрясений на расстоянии до 3000 км // Труды ИФЗ АН СССР. 1964. № 32 (199). С. 88-93].

Rikitake T., 1976. Earthquake Prediction. Elsevier, Amsterdam, 357 p.

Ryabinin G.V., Hatkevich Yu.M., 2008. Morphological types and analysis of hydrogeochemical precursors of earthquakes (case of the southeastern Kamchatka Peninsula). In: V.N. Chebrov, V.A. Saltykov (Eds), Geophysical monitoring and problems of seismic safety in the Russian Far East. Proceedings of the Regional Scientific and Technical Conference. Vol. 2. GS RAS, Petropavlovsk-Kamchatsky, p. 49-53 (in Russian) [Рябинин Г.В., Хаткевич Ю.М. Морфологическая типизация и анализ гидрогеохимических предвестников землетрясений (на примере юговосточной части полуострова Камчатка) // Геофизический мониторинг и проблемы сейсмической безопасности Дальнего Востока России: Труды региональной научно-технической конференции. Т. 2 / Ред. В.Н. Чебров, В.А. Салтыков. Петропавловск-Камчатский: ГС РАН, 2008. C. 49-53].

Ryabinin G.V., Kuzmin Yu.D., 2012. Hydrogeochemical monitoring of seismotectonic processes in Kamchatka. Current state, results, development prospects. In: E.I. Gordeev, V.N. Chebrov (Eds.), Seismological and geophysical studies in Kamchatka. Novaya Kniga, Petropavlovsk-Kamchatsky, p. 211-235 (in Russian) [Рябинин Г.В., Кузьмин Ю.Д. Гидрогеохимический мониторинг сейсмотектонических процессов на Камчатке. Современное состояние, результаты, перспективы развития // Сейсмологические и геофизические исследования на Камчатке / Ред. Е.И. Гордеев, В.Н. Чебров. Петропавловск-Камчатский: Новая книга, 2012. С. 211-235].

Semenov R.M., 2010. Earthquake of 27 August 2008 in the Southern Baikal area and its precursors. Geodynamics \& Tectonophysics 1 (4), 441-447 (in Russian) [Семенов Р.М. Землетрясение 27.08.2008 года на юге Байкала и его предвестники // Геодинамика и тектонофизика. 2010. T. 1. № 4. C. 441-447]. https://doi.org/10.5800/ GT-2010-1-4-0028.

Semenov R.M., Lopatin M.N., 2013. Search for short-term precursors of earthquakes in Southern Pribaikalie. Bulletin of the Irkutsk State University. Earth Science Series 6 (1), 183-189 (in Russian) [Семенов Р.М., Лопатин М.Н. Поиск краткосрочных предвестников землетрясений в Южном Прибайкалье // Известия Иркутского государственного университета. Серия Науки о Земле. 2013. T. 6. № 1. C. 183-189].

Semenov R.M., Smekalin O.P., 2011. The large earthquake of 27 August 2008 in Lake Baikal and its precursors. Russian Geology and Geophysics 52 (4), 405-410. https://doi. org/10.1016/j.rgg.2011.03.003.

Seminsky K.Z., Seminsky A.K., 2016. Radon in groundwaters in the Baikal region and Transbaikalia: variations in space and time. Geodynamics \& Tectonophysics 7 (3), 477493 (in Russian) [Семинский К.Ж., Семинский А.К. Радон в подземных водах Прибайкалья и Забайкалья: пространственно-временные вариации // Геодинамика и тектонофизика. 2016. Т. 7. № 3. С. 477-493]. https://doi. org/10.5800/GT-2016-7-3-0218.

Shabynin L.L., Naidich V.I., Novikov V.M., 1983. On the mechanism of formation of hydrogeochemical precursors of earthquakes. In: Hydrogeochemical studies at prognostic polygons. Abstracts of the All-Union Meeting. Nauka, Alma-Ata, p. 99-101 (in Russian) [Шабынин Л.Л., Найдич В.И., Новиков В.М. О механизме формирования гидрогеохимических предвестников землетрясений // Гидрогеохимические исследования на прогностических полигонах: Тезисы докладов Всесоюзного совещания. Алма-Ата: Наука, 1983. С. 99-101].

Sidorin A.Ya., 1979. Dependence of the time of manifestation of earthquake precursors on epicentral distance. Doklady AN SSSR 245 (4), 825-828 (in Russian) [Сидорин А.Я. Зависимость времени проявления предвестников землетрясений от эпицентрального расстояния // Доклады АН СССР. 1979. Т. 245. № 4. С. 825-828].

Sobolev G.A., 1993. Fundamentals of Earthquake Prediction. Nauka, Moscow, 313 p. (in Russian) [Соболев Г.А. Основы прогноза землетрясений. М.: Наука, 1993. 313 с.].

Tyminsky V.G., 1979. Geochemical precursors of an earthquake. Priroda (Nature) (2), 46-47 (in Russian) [Тыминский В.Г. Геохимические предвестники землетрясения // Природа. 1979. № 2. С. 46-47].

Ulomov V.I., Mavashev B.Z., 1967. On a precursor of a strong tectonic earthquake. Doklady AN SSSR 176 (2), 319321 (in Russian) [Уломов В.И., Мавашев Б.З. О предвестнике сильного тектонического землетрясения // Доклады АН СССР. 1967. Т. 176. № 2. С. 319-321].

Utkin V.I., Mamyrov E., Kan M.V., Krivasheev S.V., Yurkov A.K., Kosyakin I.I., Shishkanov A.N., 2006. Radon monitoring in the Northern Tien Shan with application to the process of tectonic earthquake nucleation. Izvestiya, Physics of the Solid Earth 42 (9), 775-784. https: / / doi.org/ 10.1134/S1069351306090072.

Vartanyan G.S., 2000. Fluidosphere, geodynamic filtration and formation of fracture permeability during subsidence of sedimentary strata. Geology, Methods of Prospecting, Exploration and Evaluation of Deposits of Fuel and Energy Raw Materials (6), 33 p. (in Russian) [Вартанян Г.С. Флюидосфера, геодинамическая фильтрация и формирование трещинной проницаемости в ходе погружения осадочных толщ // Геология, методы поисков, разведки и оценки месторождений топливно-энергетического сырья. 2000 . № 6.33 с.].

Voitov G.I., Popov E.A., 1989. Geochemical prediction of earthquakes. Priroda (Nature) (12), 60-64 (in Russian) [Войтов Г.И., Попов Е.А. Геохимический прогноз землетрясений // Природа. 1989. № 12. С. 60-64].

Wyss M., Aceves R.L., Park S.K., Geller R.J., Jackson D.D., Kagan Y.Y., Mulargia F, 1997. Cannot earthquakes be predicted? Science 278 (5337), 487-490. https://doi.org/10. 1126/science.278.5337.487.

Yanitsky I.N., 1979. Helium Survey. Nedra, Moscow, 96 p. (in Russian) [Яницкий И.Н. Гелиевая съемка. М.: Недра, 1979. 96 с.]. 


\section{RUDOLF M. SEMENOV}

Doctor of Geology and Mineralogy, Professor, Lead Researcher Irkutsk State Transport University

15 Chernishevsky St, Irkutsk 664074, Russia

Institute of the Earth's Crust, Siberian Branch of RAS

128 Lermontov St, Irkutsk 664033, Russia

e-mail: semenov@crust.irk.ru

\section{MAXIM N. LOPATIN}

Lecturer

Irkutsk State University

1 Karl Marx St, Irkutsk 664003, Russia

e-mail: flamewolf@mail.ru

\section{VLADIMIR V. CHECHELNITSKY}

Candidate of Geology and Mineralogy, Deputy Director for Science

Baikal Branch, Geophysical Survey of RAS

128 Lermontov St, Irkutsk 664033, Russia

e-mail: chechel@crust.irk.ru

\section{РУДОЛЬФ МИХАЙЛОВИЧ СЕМЕНОВ}

докт. геол.-мин. наук, профессор, в.н.с.

Иркутский государственный университет путей сообщения 664074, г. Иркутск, ул. Чернышевского, 15, Россия Институт земной коры СО РАН

664033 , г. Иркутск, ул. Лермонтова, 128, Россия

\section{МАКСИМ НИКОЛАЕВИЧ ЛОПАТИН}

преподаватель

Иркутский государственный университет

664003 , г. Иркутск, ул. Карла Маркса, 1, Россия

ВЛАДИМИР ВАСИЛЬЕВИЧ ЧЕЧЕЛЬНИЦКИЙ

канд. геол.-мин. наук, заместитель директора по научной работе

Байкальский филиал ФИЦ ЕГС РАН

664033 , г. Иркутск, ул. Лермонтова, 128, Россия 